\title{
Unresectable Small Intestinal Carcinoma
}

National Cancer Institute

\section{Source}

National Cancer Institute. Unresectable Small Intestinal Carcinoma. NCI Thesaurus. Code C8638.

Carcinoma of the small intestine not amendable to resection. 